\title{
Trastuzumab-Induced Hepatotoxicity: A Case Report
}

\author{
Darko Vucicevic $^{\mathrm{a}}$ Elizabeth J. Carey ${ }^{\mathrm{b}}$ Nina J. Karlin ${ }^{\mathrm{c}}$ \\ aDepartment of Internal Medicine, \\ ${ }^{b}$ Division of Hepatology, \\ 'Division of Hematology/Oncology, Mayo Clinic Arizona, Scottsdale, AZ, USA
}

\section{Keywords \\ Breast cancer - Trastuzumab - Liver toxicity . Hepatotoxicity}

\section{Summary}

Background: Trastuzumab is a humanized monoclonal antibody approved for the treatment of breast cancer with HER2 amplification and/or overexpression. There are only 2 prior cases of trastuzumab-related hepatotoxicity reported in the literature. Case Report: We report the case of a 60-year-old woman who was treated with trastuzumab for stage I invasive ductal carcinoma of the right breast. She successfully completed 6 months of therapy when an increase in liver transaminases was noted on routine examination. A full work-up for causes of acute and chronic liver disease was negative. After review of the patient's medication list, trastuzumab was thought to be the most likely culprit for the liver injury, based on timing of administration and rise in liver enzymes.

\section{Introduction}

Breast cancer is the most common malignancy and the second most common cause of cancer death in women [1]. 18-20\% of all invasive breast carcinomas have amplification and/or overexpression of the human epidermal growth factor 2 (HER2/ neu) gene which is associated with a more aggressive clinical course and a worse prognosis [2].

Trastuzumab is a humanized monoclonal antibody that binds to the HER2/neu protein on the breast cancer cell surface and results in growth inhibition and destruction [3].

\author{
Schlüsselwörter \\ Brustkrebs · Trastuzumab · Lebertoxizität · \\ Hepatotoxizität
}

\section{Zusammenfassung}

Hintergrund: Trastuzumab ist ein humanisierter monoklonaler Antikörper, der für die Behandlung von Brustkrebs mit HER2-Amplifikation und/oder -Überexpression zugelassen ist. Nur 2 frühere Fallberichte über eine Trastuzumab-assoziierte Hepatotoxizität sind in der Literatur zu finden. Fallbericht: Wir berichten über den Fall einer 60-jährigen Frau, die aufgrund eines invasiven duktalen Karzinoms im Stadium I in der rechten Brust mit Trastuzumab behandelt wurde. Nach 6 Monaten erfolgreicher Therapie wurden bei ihr bei einer Routineuntersuchung erhöhte Lebertransaminasenspiegel festgestellt. Eine detaillierte Testauswertung hinsichtlich möglicher Auslöser einer akuten oder chronischen Lebererkrankung ergab ein negatives Resultat. Nach eingehender Prüfung der Medikationsliste der Patientin wurde aufgrund der zeitlichen Relation zwischen der Verabreichung und der Erhöhung der Leberenzymwerte Trastuzumab als die wahrscheinlichste Ursache für die Leberschädigung angenommen.

Several phase III clinical trials have shown that the use of trastuzumab in selected patients with breast cancer improves overall survival and prolongs time to progression [4-6].

The most serious side effects of trastuzumab include congestive heart failure, interstitial pneumonitis, and infusion reaction, all of which may require temporary treatment break, or sometimes permanent discontinuation [7]. Only 2 cases of trastuzumab-induced hepatotoxicity have been reported in the literature $[8,9]$.

\section{KARGER \\ Fax +497614520714 \\ Information@Karger.com}

www.karger.com (c) 2013 S. Karger GmbH, Freiburg

$1661-3791 / 13 / 0082-0146 \$ 38.00 / 0$

Accessible online at:

www.karger.com/brc
Darko Vucicevic, MD

Department of Internal Medicine

Mayo Clinic Arizon

13400 East Shea Boulevard, Scottsdale, AZ 85259, USA

Vucicevic.Darko@mayo.edu 


\section{Case Report}

The patient is a 60-year-old woman who was diagnosed with stage I (T1a, N0, M0) invasive ductal carcinoma of the right breast. She underwent segmental mastectomy and sentinel lymph node sampling with negative margins. Her tumor was estrogen receptor positive, progesterone receptor negative, and HER2/neu overexpressing.

The patient was treated with 30 sessions of adjuvant external-beam radiation to the right breast, receiving a total of $6000 \mathrm{cGy}$. Chemotherapy was considered but was not administered due to the patient's preference. The patient was started on trastuzumab with the plan to complete 52 weeks of therapy. Trastuzumab was administered every 3 weeks, with an initial loading dose of $8 \mathrm{mg} / \mathrm{kg}$ and subsequent doses of $6 \mathrm{mg} / \mathrm{kg}$. She was also started on the aromatase inhibitor exemestane, at the dose of $25 \mathrm{mg}$ daily.

The patient successfully completed 8 cycles of trastuzumab therapy during the course of 6 months when an increase in liver transaminases was noticed (aspartate transaminase (AST) $93 \mathrm{U} / \mathrm{L}$ (8-43), alanine transaminases (ALT) $91 \mathrm{U} / \mathrm{L}$ (7-45)). Alkaline phosphatase (AP), coagulation panel and bilirubin levels were within normal limits at the time. The repeat examination 1 week later showed a further rise in the liver function tests (AST 206, ALT 260). The patient did not have any prior history of liver disease or alcohol use. Due to the development of transaminitis, the decision was made to hold further trastuzumab. A work-up for causes of acute and chronic liver disease was negative (table 1). Doppler ultrasound of the liver was unremarkable.

The liver enzymes peaked 2 months after the last trastuzumab infusion (AST 437, ALT 523, AP 231, total bilirubin 1.0, prothrombin time (PT)/international normalized ratio (INR) 12.5/0.94). The timeline of the elevation of the liver function tests in relation to trastuzumab administration can be seen in figure 1 . The progressive rise of liver enzymes in the absence of a diagnosis led to a liver biopsy. The histopathologic review of the tissue showed acute hepatitis of moderate activity, with portal infiltrates comprising lymphocytes, plasma cells, and eosinophils. The morphologic findings favored drug reaction.

After careful review of the patient's medication list, trastuzumab was thought to be the most likely culprit for the elevated liver test results, based on the timing of administration and rise in liver enzymes. The patient had been treated with intravenous vancomycin and ertapenem for right breast mastitis 3 weeks prior to the initial rise in liver enzymes. Neither of these agents is known to cause significant liver dysfunction per the Food and Drug Administration (FDA) side effect profile. Furthermore, it would be unusual for antibiotics with a short half-life to cause delayed hepatotoxicity. Throughout the described clinical course, the

Table 1. Laboratory work-up of elevated hepatic function tests

\begin{tabular}{ll}
\hline Test & Result \\
\hline Hepatitis Bs antibody & indeterminate \\
Hepatitis Bs antigen & negative \\
Hepatitis Bc IgM antibody & negative \\
Hepatitis Bc IgG, IgM antibody & positive \\
Hepatitis B DNA & undetected \\
Hepatitis E IgG antibody & negative \\
Hepatitis E IgM antibody & negative \\
Hepatitis C antibody & negative \\
Hepatitis C RNA & undetectable \\
Hepatitis A IgM antibody & negative \\
Anti-smooth muscle antibodies & negative \\
Antimitochondrial antibodies & negative \\
Antinuclear antibody & negative \\
Ferritin and iron levels & normal \\
\hline Ig = Immunoglobulin. & \\
\hline
\end{tabular}

Trastuzumab-Induced Hepatotoxicity

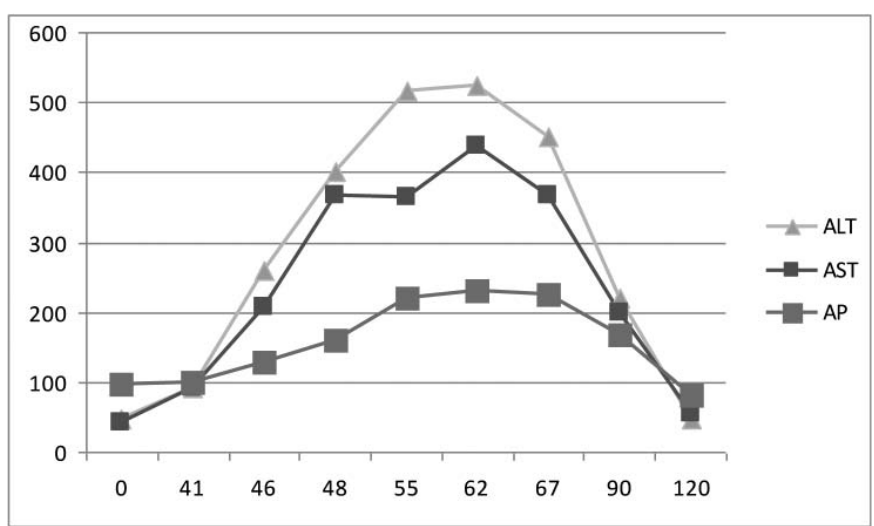

Fig. 1. Timeline of the liver function test abnormality. The last dose of trastuzumab was received on day 0 . The $\mathrm{x}$-axis represents time in days. Total bilirubin and INR remained within normal limits throughout the follow-up period. AST $=$ Aspartate transaminase, ALT $=$ alanine transaminases, $\mathrm{AP}=$ alkaline phosphatase.

patient continued to take the aromatase inhibitor, exemestane. This medication was deemed not to be the cause of the hepatic injury since, with exemestane, one would expect a cholestatic pattern of liver injury, which was not the case with our patient.

During the next month, the liver enzymes started to trend down (AST 199, ALT 221, AP 163), with near normalization (AST 54, ALT 46, AP 81) 4 months after the last dose of trastuzumab. Due to the low-grade tumor and significant hepatitis, the decision was made that the patient should not be re-challenged with this targeted agent.

\section{Discussion}

According to the validated drug-induced hepatotoxicity scales [10-13], certain criteria should be met in order to prove that a liver injury is caused by the medication: (1) There should be a clear time correlation between administration of the drug and hepatic injury, (2) the liver enzymes should trend down with drug withdrawal, (3) other causes of hepatitis should be excluded, and (4) the abnormality should be reproduced with re-challenge. Although recurrence of hepatitis upon re-challenge is diagnostic of drug-induced liver injury (DILI), rechallenge is generally discouraged except when the drug is considered essential [14]. In this case, the patient developed hepatotoxicity 6 months after the initial trastuzumab dose. Trastuzumab has a high volume of distribution and a relatively long half-life, which may explain the prolonged time to liver injury. Furthermore, cardiac dysfunction, the mostfeared complication of trastuzumab administration, can happen up to 9 months following the initiation of treatment. The liver enzymes started to trend down after the medication was stopped, in a timeline that would correspond to half-life elimination of trastuzumab, which can last up to 23 days. No other cause of liver injury was found as discussed above and no other offending medications could be identified. 
Only 2 prior cases of trastuzumab-induced hepatotoxicity have been reported in the literature. In the 1st case, a patient with advanced breast cancer was treated with adjuvant chemotherapy followed by administration of paclitaxel and trastuzumab. Liver injury occurred 1 month after the initiation of treatment with trastuzumab and normalized 2 weeks after discontinuation of the therapy. Re-challenge with trastuzumab yielded another rise in the liver function tests [8]. The 2nd case discussed trastuzumab hepatotoxicity in a patient with advanced breast cancer; however, reintroduction of trastuzumab did not cause a significant rise in the liver function tests and the patient was able to complete 1 year of treatment [9]. Randomized controlled trials assessing the efficacy of trastuzumab did not report hepatotoxicity as a side effect [4-6].
To our knowledge, this is the $3 \mathrm{rd}$ case report discussing trastuzumab-induced hepatotoxicity. Although a rare complication, liver injury may result in permanent discontinuation of the treatment with trastuzumab and limit the options for further therapy in patients with advanced breast cancer. We advocate obtaining the baseline hepatic function panel prior to initiation of treatment and following the liver enzymes on a monthly basis during the whole treatment course with trastuzumab.

\section{Disclosure Statement}

The authors do not have any sponsorship/financial arrangements related to the research or conflicts of interest to disclose.

\section{References}

1 Jemal A, Siegel R, Xu J, Ward E: Cancer statistics, 2010. CA Cancer J Clin 2010;60:277-300; Erratum in CA Cancer J Clin 2011;61:133-134.

$\checkmark 2$ Daniele L, Sapino A: Anti-HER2 treatment and breast cancer: State of the art, recent patents, and new strategies. Recent Pat Anticancer Drug Discov 2009;4:9-18.

3 Albanell J, Codony J, Rovira A, Mellado B, Gascon P: Mechanism of action of anti-HER2 monoclonal antibodies: Scientific update on trastuzumab and 2C4. Adv Exp Med Biol 2003;532:253268.

4 Romond EH, Perez EA, Bryant J, Suman VJ, Geyer CE Jr, Davidson NE, Tan-Chiu E, Martino S, Paik S, Kaufman PA, Swain SM, Pisansky TM, Fehrenbacher L, Kutteh LA, Vogel VG, Visscher DW, Yothers G, Jenkins RB, Brown AM, Dakhil SR, Mamounas EP, Lingle WL, Klein PM, Ingle JN, Wolmark N: Trastuzumab plus adjuvant chemotherapy for operable HER2positive breast cancer. N Engl J Med 2005;353: 1673-1684.

5 Piccart-Gebhart MJ, Procter M, Leyland-Jones B, Goldhirsch A, Untch M, Smith I, Gianni L, Baselga J, Bell R, Jackisch C, Cameron D, Dowsett M,
Barrios CH, Steger G, Huang CS, Andersson M, Inbar M, Lichinitser M, Lang I, Nitz U, Iwata H, Thomssen C, Lohrisch C, Suter TM, Ruschoff J, Suto T, Greatorex V, Ward C, Straehle C, McFadden E, Dolci MS, Gelber RD, Herceptin Adjuvant Trial Study T: Trastuzumab after adjuvant chemotherapy in HER2-positive breast cancer. N Engl J Med 2005;353:1659-1672.

6 Smith I, Procter M, Gelber RD, Guillaume S, Feyereislova A, Dowsett M, Goldhirsch A, Untch M, Mariani G, Baselga J, Kaufmann M, Cameron D, Bell R, Bergh J, Coleman R, Wardley A, Harbeck N, Lopez RI, Mallmann P, Gelmon K, Wilcken N, Wist E, Sanchez Rovira P, Piccart-Gebhart MJ, HERA study team: 2-Year follow-up of trastuzumab after adjuvant chemotherapy in HER2-positive breast cancer: A randomised controlled trial. Lancet 2007;369:29-36.

7 Lin A, Rugo HS: The role of trastuzumab in early stage breast cancer: Current data and treatment recommendations. Curr Treat Options Oncol 2007; 8:47-60.

8 Srinivasan S, Parsa V, Liu CY, Fontana JA: Trastuzumab-induced hepatotoxicity. Ann Pharmacother 2008:42:1497-1501.
9 Munoz A, Carrera S, Ferreiro J, de Lobera AR, Mane JM, Lopez-Vivanco G: Reversible liver toxicity with adjuvant trastuzumab for localized breast cancer. Ann Oncol 2007;18:2045-2046.

10 Danan G, Benichou C: Causality assessment of adverse reactions to drugs - I. A novel method based on the conclusions of international consensus meetings: Application to drug-induced liver injuries. J Clin Epidemiol 1993;46:1323-1330.

11 Benichou C: Criteria of drug-induced liver disorders. Report of an international consensus meeting. J Hepatol 1990;11:272-276.

12 Maria VA, Victorino RM: Development and validation of a clinical scale for the diagnosis of drug-induced hepatitis. Hepatology 1997;26:664669.

13 Hayashi PH: Causality assessment in drug-induced liver injury. Semin Liver Dis 2009;29:348-356.

14 Hunt CM: Mitochondrial and immunoallergic injury increase risk of positive drug rechallenge after drug-induced liver injury: A systematic review. Hepatology 2010;52:2216-2222. 